\title{
PRINCÍPIO DA PRECAUÇÃO, IRREPARABILIDADE DOS DANOS AMBIENTAIS E TUTELA DO MEIO AMBIENTE
}

\author{
PRINCIPLE OF PRECAUTION, IRREPARABILITY OF ENVIRONMENTAL DAMAGE \\ AND ENVIRONMENTAL PROTECTION
}

\author{
Tamires Ravanello \\ Universidade de Caxias do Sul \\ Mestre em Direito Ambiental pela Universidade de Caxias do Sul \\ tami_ravanello@hotmail.com \\ Carlos Alberto Lunelli \\ Universidade de Caxias do Sul \\ Doutor em Direito pela Universidade do Rio dos Sinos \\ calunelli@gmail.com
}

\begin{abstract}
Resumo: O homem, desde os primórdios, degradou o ambiente, causando diversos reflexos negativos. Uma vez lesado o meio ambiente, torna-se muito difícil, ou mesmo impossível, retornar ao estado anterior. Ademais, a reparação pecuniária não se mostra equivalente, vez que o meio ambiente não possui valor monetário. O Princípio da Precaução, enquanto medida preventiva, pode ser medida efetiva para a preservação ambiental. O artigo objetiva analisar o dever de preservação ambiental ante à sua degradação, verificando a previsão constitucional e infraconstitucional em relação ao Princípio da Precaução, além de analisar se o princípio é medida efetiva na proteção do meio ambiente, para tanto, o método abordado será o hermenêutico. Concluiu-se que, o Princípio da Precaução, ao permitir a tomada de medidas que evitem danos ao ambiente, mesmo sem certeza científica, é meio hábil para tutelar o meio ambiente, não podendo, contudo, dissociar-se da proporcionalidade.
\end{abstract}

Palavras-chave: Princípio da Precaução. Preservação Ambiental. Tutela Ambiental. Meio Ambiente.

Abstract: Since the beginning of time, man has been degrading the environment, causing several negative reflexes. Once the environment is damaged, it is very difficult, or even impossible, to return to the previous state. Furthermore, the financial reparation is not equivalent, since the environment has no monetary value. The precautionary principle, as a preventive measure, can be an effective measure for environmental preservation. The article aims to analyze the duty to environmental preservation concerning its degradation, checking the constitutional provision and infraconstitutional related to the precautionary principle, in addition to analyzing whether the principle is an effective measure in the protection of the environment, for that, the approached method will be the hermeneutic. It was concluded that the precautionary principle, in allowing to take measures to avoid damage to the environment, even without scientific certainty, is a good way to protect the environment, however, it cannot be dissociated from proportionality.

Keywords: Principle of Precaution. Environmental Preservation. Environmental Custody. Environment.

\section{Para citar este artigo}

ABNT NBR 6023:2018

RAVANELLO, Tamires; LUNELLI, Carlos Alberto. Princípio da precaução, irreparabilidade dos danos ambientais e tutela do meio ambiente. Prisma Jurídico, São Paulo, v. 19, n. 1, p. 138-152, jan./jun. 2020. http://doi.org/10.5585/prismaj.v19n1.10469. 


\section{Introdução}

A degradação ambiental é alvo das discussões atuais, pois o ambiente é o propulsor da sobrevivência da vida humana. Em que pese a extrema importância do meio ambiente, o homem, desde os primórdios, degradou o seu habitat, causando esgotamento de recursos, extinção de espécies, poluição e mudanças climáticas. O meio ambiente foi encoberto pelos interesses econômicos, sendo os danos ambientais, constantes.

Entretanto, uma vez lesado o meio ambiente, é muito difícil para o mesmo, ou mesmo impossível, retornar ao estado anterior. Da mesma forma, a reparação pecuniária não se mostra equivalente, vez que o meio ambiente não possui valor monetário. Diante disso, as medidas preventivas são as maneiras mais eficazes para a preservação ambiental.

Uma importante ferramenta preventiva pode ser o Princípio da Precaução, princípio do Direito Ambiental, que, embora não conste de forma expressa na Constituição Federal, pode ser deduzido do texto constitucional, bem como, de diversos dispositivos da legislação infraconstitucional.

O Princípio da Precaução possui o objetivo geral de preservar o meio ambiente, porque dispõe sobre a incerteza científica de não poder ser tomada como desculpa para que nenhuma medida seja tomada. Assim, quando houver evidência de risco de dano grave, de difícil ou impossível reparação, medidas precaucionais deverão ser adotadas.

Tendo em vista, a relevância da preservação ambiental, que atualmente é tema central das discussões mundiais, destaca-se a importância da temática desenvolvida, vez que o Princípio da Precaução pode ser importante ferramenta na cautela dos riscos e por consequência, na preservação do meio ambiente.

Através do estudo, pretende-se responder se o Princípio da Precaução é medida que contribui para a preservação ambiental. Para tanto, será abordada a problemática da degradação ambiental e a necessária preservação ambiental, o Princípio da Precaução na legislação, especialmente no âmbito constitucional e a relevância do Princípio da Precaução na defesa do meio ambiente.

O método abordado será o hermenêutico, que se desenvolve através de operação de compreensão e interpretação. A pesquisa será desenvolvida por meio da técnica de revisão bibliográfica de autores que escreveram sobre a temática, utilizando doutrina, artigos científicos e legislação.

O estudo abordará, primeiramente, sobre a necessidade de preservação do meio ambiente ante à degradação, destacará a importância dos princípios ambientais, em especial o 
Princípio da Precaução, destacando sua afirmação constitucional e, por fim, ressaltará a importância do Princípio da Precaução demonstrando sua relevância na prevenção de danos e por consequência, na preservação do meio ambiente.

\section{Necessidade de preservação do meio ambiente ante a degradação da qualidade ambiental}

A ocupação humana degrada o meio ambiente causando alterações que ameaçam a qualidade de vida humana e sua própria sobrevivência. Dessa forma, demonstra-se a preocupação com as questões ambientais e a necessidade de preservação.

Primeiramente importa conceituar meio ambiente. A Lei ${ }^{\circ} 6.938 / 81$, em seu art. $3^{\circ}, \mathrm{I}$, definiu o conceito de meio ambiente como sendo o conjunto de condições, leis, influências e interações de ordem física, química e biológica, que permite, abriga e rege a vida em todas as suas formas.

O meio ambiente é um bem que pertence à coletividade, não integrando, assim, o patrimônio do Estado. A fruição do meio ambiente é de todos e, em contrapartida, o dever jurídico de protegê-lo também é de toda a coletividade, podendo ser exercido pelo indivíduo, pelas associações, pelo Ministério Público ou pelo Estado.

Não obstante a preservação ambiental ser dever de todos, o meio ambiente sempre foi alvo das transformações humanas. Nos primórdios, as alterações eram discretas, mas logo passaram a ser brutais, maciças e dominadoras.

Os desajustes entre desenvolvimento econômico e equilíbrio ecológico não são recentes. As civilizações dos trópicos geraram processos populacionais e formas de apropriação de seu meio que destruíram seu habitat e, por conseguinte, conduziram ao seu próprio colapso. No entanto, hoje, pela primeira vez na história, esse processo de desequilíbrio adquire uma dimensão global. Nesse sentido, Leff (2001) afirma que não se trata apenas de um território ou cultura, mas um processo geral, destruindo o habitat e as formas sustentáveis de organização. No mesmo sentido, Mateo (1991, p. 33) aponta que: "El hombre de hoy usa y abusa de la naturaleza como si hubiera de ser el último inquilino de este desgraciado planeta, como si detrás de él no se anunciara un futuro. La naturaleza se convierte así en el chivo expiatorio del progreso."1

O crescimento econômico, objetivo da humanidade, desenvolveu-se através da transformação destrutiva dos recursos naturais. A regra sempre foi o acúmulo de capital e a

\footnotetext{
1 "O homem de hoje usa e abusa da natureza como se fosse o último inquilino deste desgraçado planeta, como se por trás dele não se anunciasse um futuro. A natureza se converte assim, em crivo expiatório do progresso.” (Tradução nossa).
} 
produção de riqueza, ignorando-se a preservação dos recursos naturais, como elemento de uso limitado. Assim, para Leite e Ayala (2014), os recursos naturais não são contabilizados no sistema econômico e, como consequência, a defesa do meio ambiente e o crescimento econômico são vistos como inconciliáveis e excludentes.

É possível afirmar que o planeta vive uma crise ecológica. A ação humana causou devastação, destruiu diversas espécies de animais e promoveu o esgotamento de recursos naturais. Segundo Ost (1997), essa crise é, sobretudo, uma crise de representação da natureza, ou melhor, é uma crise da relação do ser humano com a natureza.

A degradação ambiental manifesta-se como sintoma de uma crise de civilização, marcada pelo modelo de modernidade regido pelo predomínio do desenvolvimento da tecnologia e dos interesses econômicos sobre a organização da natureza. A crise ambiental é a crise desse tempo, é o efeito do pensamento com o qual se constrói e se destrói o mundo (LEFF, 2001).

Em vista do aumento da produtividade, os riscos foram deixados de lado, entretanto, os riscos não possuem limitação espacial e temporal, os perigos são cumulativos e seu potencial destrutivo é muito grande, podendo ocasionar catástrofes de extensão global. Ademais, observa-se que os riscos são percebidos muito tarde, geralmente quando o dano já ocorreu, ou não pode mais ser evitado (SILVEIRA, 2014). No mesmo sentido argumenta Beck (2012):

\footnotetext{
Os riscos e ameaças atuais diferenciam-se, portanto, de seus equivalentes medievais, com frequência semelhante por fora, fundamentalmente por conta da globalidade de seu alcance (ser humano, fauna, flora) e de suas causas modernas. São riscos da modernização. São um produto de série do maquinário industrial do progresso, sendo sistematicamente agravados com seu desenvolvimento ulterior. (BECK, 2012, p. 26, grifo do autor).
}

Nessa sequência, em se tratando de meio ambiente, havendo probabilidade de acidentes, mesmo sendo reduzida, deve ser considerada alta demais quando um acidente ambiental pode significar extermínio. Considera-se, portanto, que os riscos são importantes de mais e as consequências graves demais para aguardar provas conclusivas e consenso científico geral, em torno delas (ARAGÃO, 2008).

Para Beck (2012), riscos indicam um futuro que precisa ser evitado. Segundo o autor, riscos se relacionam com antecipação, com destruição que ainda não ocorreram, mas que são iminentes, e que, por esse motivo, já são reais.

Não se trata de proibir toda a atividade humana, no entanto, é necessário estabelecer um limite. Quando são concedidas autorizações para atividades perigosas ou poluentes, por 
exemplo, devem ser acompanhadas de prescrições técnicas que condicionem a licença, dispondo de um nível de risco aceitável para a coletividade e de poluição tolerável para o meio (OST, 1997).

Para Mateo (1991), as dificuldades se acentuam quando se verificam que os conhecimentos científicos atuais não permitem estabelecer com precisão quando haverá um dano ambiental que seja nocivo e irreversível. Esses fatos, têm dado lugar ao posicionamento de ambientalistas que propõem uma margem de segurança que cubra riscos previsíveis ainda que não detectados com precisão.

O direito ambiental, sob a perspectiva emancipatória da sociedade de risco, tende a evitar que os danos ocorram, impedindo os atos que causem degradação ambiental, mesmo quando as consequências não são claras. Desse modo, a prevenção é o antídoto jurídico para o risco determinado por atos (BELLO FILHO, 2004). Isso deve-se sobretudo ao fato de que a degradação ambiental ameaça não somente o bem-estar e a qualidade de vida humana, mas também a própria sobrevivência do ser humano.

Observa-se que a degradação ambiental é constante, os danos ambientais são crescentes em quantidade e magnitude e a humanidade vive ameaçada pelos riscos. Diante desse cenário, faz-se necessária uma maior preservação do meio ambiente, o que pode ocorrer através de medidas precaucionais como o Princípio da Precaução.

\section{Afirmação do princípio da precaução na legislação}

A questão ambiental é circundada por ampla produção legislativa, no entanto, ela não é capaz de atender a todas as diferentes situações que surgem no decorrer do tempo. Ademais, o simples reconhecimento do direito fundamental ao meio ambiente, ainda que sustentado pela legislação, é insuficiente para produzir a sua efetiva proteção. Assim, a legislação apresenta-se como uma falsa ideia de proteção do bem ambiental (LUNELLI, 2015).

Diante dessas dificuldades, os princípios de Direito Ambiental ganham relevância, pois é por meio deles que as matérias que ainda não foram objeto de legislação específica podem ser tratadas pelos aplicadores do Direito, vez que, não havendo norma legal, recorrese aos diferentes elementos formadores do Direito (ANTUNES, 2014).

Princípios, segundo Canotilho (2008), são construções teóricas que tendem a desenvolver uma base comum nos instrumentos normativos de política ambiental. Segundo o autor, princípios servem para balizar a atuação do Estado em relação à tutela do ambiente, além de dar um sentido lógico e coerente ao sistema. 
A Constituição Federal de 1988 congrega diversos princípios ambientais, de forma expressa ou implicitamente, gerais ou específicos. Pode-se citar, a título exemplificativo, o princípio do uso sustentável dos recursos naturais, o princípio da prevenção, princípio do poluidor-pagador e princípio do usuário-pagador.

Tanto os princípios explícitos quanto os implícitos são dotados de positividade, devendo ser levados em consideração pelo aplicador do direito, não apenas no âmbito do Poder Judiciário, como também pelo Executivo e Legislativo.

Segundo Antunes (2014), o recurso aos princípios jurídicos não é uma tarefa simples, pois, não há sequer consenso doutrinário sobre quais seriam os princípios aplicáveis ao Direito Ambiental. No entanto, alguns são amplamente aceitos, ainda que haja divergência quanto ao seu significado.

Nessa sequência, cita-se um importante princípio do direito ambiental, o Princípio da Precaução, tema de divergência quanto à sua previsão e modo de aplicação, entretanto, incontroversa é sua relevância na defesa do meio ambiente.

O Princípio da Precaução não consta de forma expressa na Constituição Federal de 1998, tal fato pode ser atribuído ao precário desenvolvimento doutrinário do princípio naquela época. Entretanto, o princípio pode ser extraído pela interpretação do texto constitucional, quando se analisa a intenção do Poder Constituinte Originário em proteger a saúde pública e o meio ambiente de danos e de impedir a violação dos direitos da criança e do adolescente.

Assim, em que pese o Princípio da Precaução não estar expresso na Constituição de 1988, é frequentemente deduzido do art. 225, §1², II a V. Morato Leite (2008), possui posicionamento semelhante, segundo o autor, de que o Princípio da Precaução emana de vários dispositivos constitucionais, especialmente do art. 225. Assim, para ele, o princípio está claramente incorporado ao sistema, exercendo função normativa relevante.

Segundo Leme Machado (2014), ao ser incorporada à metodologia das medidas liminares à Constituição, como forma de proteger o homem e a biota, mesmo não mencionando o Princípio da Precaução de forma expressa, é inegável que está contido no art, $225, \S 1^{\circ}, \mathrm{V}$ e VII, pois tende à prevenção dos riscos ambientais.

Conforme o entendimento de Santilli (2005), o Princípio da Precaução demonstra-se ainda no ordenamento constitucional através da obrigação de realização do estudo prévio de impacto ambiental para as atividades degradadoras do meio ambiente.

Mediante a interpretação da Constituição de 1988, é possível sustentar que o Princípio da Precaução é deduzido do conjunto das disposições constitucionais que versam sobre o direito ao meio ambiente equilibrado. Assim, em que pese o princípio não estar previsto de 
forma expressa, muitos autores têm sustentado que o princípio em estudo decorre do sistema pátrio de proteção jurídica do meio ambiente.

$\mathrm{Na}$ legislação infraconstitucional, o princípio foi consagrado no art. $2^{\circ}$ do Decreto Federal $\mathrm{n}^{\circ}$ 5.098/2004 (Plano Nacional de prevenção, preparação e resposta rápidas e emergências ambientais com produtos químicos perigosos) tratando de acidentes com cargas perigosas.

Está previsto na Lei $\mathrm{n}^{\circ}$ 6.938/81, que dispõe sobre a Política Nacional do Meio Ambiente, a qual tende a precaver a sociedade contra possíveis danos que possam ser causados ao meio ambiente e tem como objetivo a preservação e a recuperação da qualidade ambiental propícia à vida.

O princípio foi consagrado expressamente no art. $54, \S 3^{\circ}$, da Lei $\mathrm{n}^{\circ}$ 9.605/98 (Lei de Crimes Ambientais), que penaliza criminalmente quem deixar de adotar medidas precaucionais exigidas pelo Poder Público, prevendo pena privativa de liberdade e multa às pessoas físicas ou jurídicas que causarem, através de ação ou omissão, poluição de qualquer natureza em níveis que resultem danos à vida humana, provoquem a mortandade de animais ou a destruição da flora.

A mesma lei acima referida, prevê ainda em seu art. 70, que a violação do Princípio da Precaução pode ocasionar uma infração administrativa, dispondo que "Considera-se infração administrativa ambiental toda ação ou omissão que violar normas jurídicas de uso, gozo, promoção, proteção e recuperação do meio ambiente."

Destaca Nogueira (2004), ainda, que o Brasil assinou e ratificou a Convenção-Quadro das Nações Unidas sobre Mudança do Clima, produto da Conferência das Nações Unidas sobre Meio Ambiente e Desenvolvimento de 1992, que enuncia expressamente, em seu artigo $3^{\circ}$, o Princípio da Precaução. Assim, segundo a autora, é possível afirmar que o princípio em comento foi inquestionavelmente incorporado ao ordenamento jurídico nacional.

Ademais, há uma tendência de dilatação do Princípio da Precaução em diversos campos do direito. Posto ter surgido num contexto ambiental, o princípio vem sendo aplicado em diferentes contextos, além de temas próximos como saúde pública e proteção dos consumidores, tem sido invocado ainda em matérias de comércio internacional e até no direito de família (ARAGÃO, 2008).

O Princípio da Precaução é regra de Direito Internacional disposto em diversas legislações, tratados e Convenções Internacionais, e tem sido invocado, inclusive, na Corte Internacional de Justiça de Haia, o que demonstra seu amplo reconhecimento (WEDY, 2009).

Destaca-se, sobretudo, a elevada importância que o princípio possui no Direito 
europeu. Fato esse, que é demonstrado pelo grande número de documentos oficiais em vigor que fazem referências diretas à precaução, os quais totalizam um número de 301 e que fazem dele um princípio fundamental (ARAGÃO, 2008).

Assim, não resta dúvida quanto à adoção do Princípio da Precaução na legislação constitucional, ainda que não conste de forma expressa na Constituição Federal de 1988, é visivelmente deduzido da interpretação do texto constitucional. Além disso, é amplamente adotado na legislação infraconstitucional. Demonstra-se, dessa forma, a importância do Princípio da Precaução, vez que é considerado instrumento à tutela do meio ambiente, seguindo, inclusive, uma tendência internacional.

\section{Relevância do princípio da precaução na proteção ambiental}

O Princípio da Precaução surgiu no direito alemão na década de 70, visando a proteção ambiental, o chamado Vorsorgeprinzip. Seu marco inicial é a lei federal alemã de proteção contra emissões, datada de 1974 (SILVEIRA, 2014).

Na década de 90, o princípio começa a ganhar maior reconhecimento doutrinal e passa a ser consagrado com mais frequência em instrumentos de Direito Internacional. Desse modo, considera-se que o Princípio da Precaução é relativamente recente no campo ambiental, entretanto, tem-se expandido com rapidez, sendo introduzido em diversos instrumentos com larga aceitação da doutrina. Seu enunciado mais conhecido é do princípio 15 da Declaração do Rio de Janeiro sobre Meio Ambiente e Desenvolvimento, o qual prescreve que:

Com o fim de proteger o meio ambiente, o Princípio da Precaução deverá ser amplamente observado pelos Estados, de acordo com suas capacidades. Quando houver ameaça de danos graves ou irreversíveis, a ausência de certeza científica absoluta não será utilizada como razão para o adiamento de medidas economicamente viáveis para prevenir a degradação ambiental. (RIO DE JANEIRO, 1992, p. 3).

O Princípio da Precaução possui como principal característica, a proteção do ambiente apesar da incerteza científica. "Em uma definição do Princípio da Precaução tem de fícar clara a atitude de antecipação do risco de dano grave, de difícil reparação ou até irreparável." (LOPEZ, 2010, p. 98-99).

Por conseguinte, importante diferenciar o Princípio da Precaução do princípio da prevenção. Embora os dois princípios operem no sentido de evitar os danos ambientais, visto constituírem instrumentos que se antecedem à ocorrência dos fatos danosos, eles não se confundem. 
Para Lopez (2010), a diferença entre a precaução e a prevenção reside na diferença entre o risco potencial e o risco provado. Enquanto a primeira diz respeito aos riscospotenciais, na última, os riscos são conhecidos e provados.

Para Aragão (2008), ainda que ambos sejam manifestações modernas da ideia de defesa e prudência ambiental, elas distinguem-se pelas condições de aplicação e pela natureza das medidas que promovem. Segundo a autora, a precaução destina-se a limitar riscos hipotéticos ou potenciais, enquanto a prevenção visa controlar os riscos comprovados. Por isso, para a autora, o Princípio da Precaução é proativo e o princípio da prevenção é reativo.

Conforme Silveira (2014), a ação precaucional impõe prudência diante de danos graves ou irreversíveis, difíceis de comprovar. Por outro lado, a prevenção atua a partir de danos conhecidos, os quais são comprovados cientificamente e mensuráveis.

Nessa sequência, a precaução permite problematizar os rumos da ciência e da tecnologia, expor os limites do desenvolvimento e a irreversibilidade dos danos ao ambiente e, reconhecer os riscos das ações humanas, que podem fugir de controle. Assim, é preciso levar a sério as ameaças e antecipá-las, mesmo quando não comprovadas ou não mensuráveis (SILVEIRA, 2013).

A proteção ambiental deve ocorrer apesar da incerteza científica, ou seja, há um dever de preservação não só em nome das gerações presentes, mas também das futuras, haja vista o princípio do desenvolvimento sustentável e do princípio da solidariedade intergeracional (WEDY, 2009).

O Princípio da Precaução estabelece um dever de problematizar os riscos. Para Silveira (2013), é necessário proibir a utilização da incerteza científica como desculpa, é preciso colocar em pauta os riscos produzidos, definir responsabilidades e decidir acerca de cenários toleráveis e intoleráveis.

O Princípio da Precaução não estabelece quais medidas devem ser tomadas, apenas afirma que a inércia não é aceitável. Desse modo, o princípio “[...] é um instrumento apropriado para situações de incerteza, visto que não é rígido e porque permite em cada caso seu peso concreto, equilibrando com outros argumentos competitivos." (LORENZETTI, 2010, p. 81).

Por conseguinte, além da aceitação do Princípio da Precaução é necessário avançar para a fase de implementação, a fim de tornar uma realidade possível e não apenas uma declaração politicamente correta, mas que não é aplicável. 
O Princípio da Precaução é alvo de interpretações e aplicações diversas, reflexo do choque entre o conhecimento científico e técnico com conteúdo das regras jurídicas e dos processos de tomada de decisão (THORSTENSEN; MOTA; ARIMA JR., 2019).

A aplicação deve ser de modo adaptativo, ou seja, não deve haver decisões definitivas, as medidas adotadas podem ser revistas total ou parcialmente, por meio de um monitoramento constante. Isso deve-se à possibilidade de os conhecimentos científicos serem aprimorados, assim, medidas podem ser modificadas conforme o surgimento de novas informações sobre o assunto.

Por outro lado, deve-se ter presente que uma vez ocasionado um dano ambiental, ele deve ser reparado integralmente, aproximando-se ao máximo possível da situação anterior ao dano, tendo presente a necessidade de uma compensação ampla da lesão sofrida. Entretanto, há imensa dificuldade em se apurar o ressarcimento do dano ambiental, devido às barreiras na avaliação econômica do bem ambiental e na sua difícil reposição.

A reparação in natura é considerada indispensável à compensação do prejuízo ambiental. A reparação natural do dano, via de regra, exige do responsável uma prestação positiva, ou seja, a imposição do cumprimento de uma obrigação de fazer, constituindo a reparação in natura, pretendendo a restituição do meio ambiente agredido ao estado anterior à ocorrência da degradação (MIRRA, 2004).

No tocante à reparação pecuniária dos danos ambientais, as dificuldades são marcantes, tendo em vista que a conversão monetária para fins de cálculo indenizatório é, na maioria dos casos, impossível.

Sanções pecuniárias procedem em saldo negativo ao ecossistema, tendo em vista que os seres humanos perdem a sua dignidade e a natureza tem um déficit no número de espécies e um desequilíbrio nas relações ecológicas (MAZUR; MOURA, 2019).

Em se tratando de meio ambiente, não há um valor por equivalência, nem tampouco por satisfação. Deve-se proceder, em primeiro lugar, à prevenção, logo a recomposição e finalmente, a reparação. Devido à gravidade dos danos ambientais, há que se prevenir antes de ressarcir e se recompor antes de indenizar.

Ao constatar que as agressões ao ambiente são de reparação difícil, incerta e custosa, deve-se seguir uma conduta de in dubio pro ambiente. Isso significa que o ambiente deve prevalecer sobre uma atividade de perigo ou risco, mesmo que não haja certeza científica sobre o liame da causalidade e os seus efeitos. Devem ser considerados não só os riscos ambientais iminentes, mas também os perigos futuros provenientes de atividades humanas 
que possam vir a comprometer a relação intergeracional e de sustentabilidade ambiental (LEITE, 2008).

Nessa sequência, demonstra-se a importância do Princípio da Precaução na proteção ambiental, sobretudo, pelo fato da reparação e a compensação serem um caminho inadequado quando se trata de meio ambiente. Dessa forma, a prevenção deve ser priorizada.

A precaução separa o Direito Ambiental de outras disciplinas jurídicas tradicionais como o Direito Penal e o Direito Civil, que no passado, eram as únicas que se prestavam a lidar com problemas ambientais. Segundo Benjamin, “[...] a responsabilização civil e criminal clássica têm como pré-requisitos fundamentais "certeza" e "previsibilidade"; exatamente dois dos obstáculos que a norma ambiental, com a precaução, procura afastar.” (BENJAMIN, 2008, p. 20).

Adverte-se, no entanto, que a aplicação do Princípio da Precaução não pode dissociarse da proporcionalidade. A medida de precaução deve ser proporcional ao risco alegado, ou seja, a autoridade pública deve escolher a ação que seja efetivamente necessária para assegurar a proteção ambiental (NOIVILLE, 2005) .

A precaução implica em agir com moderação, ou seja, dentre os meios hábeis a evitar o risco de dano. Deve-se optar pelos menos gravosos àqueles que terão seus interesses atingidos. Nesse seguimento, a ponderação de valores e o princípio da proporcionalidade são instrumentos para a segura implementação do princípio de precaução. Para Wedy (2009),

A ponderação de valores deve ser realizada quando, na aplicação do princípio, estiverem em conflito bens constitucionalmente protegidos. A tutela do meio ambiente e da saúde pública não pode ser levada ao extremo a ponto de anular bens e valores constitucionalmente relevantes, como a propriedade privada, a livreiniciativa e o desenvolvimento econômico. (WEDY, 2009, p. 185).

Para Silveira (2014, p. 268), é necessário atuar com cautela, mas essa atitude precaucional "[...] não se traduz em negação do empreendimento ou atividade acautelada, significa ponderar riscos em toda a sua complexidade; debater a partir de diagnósticos e da produção de cenários; deliberar sobre níveis adequados de proteção, medidas cabíveis." Assim, para o autor, atuar com cautela é conferir um sentido coletivo à atividade em pauta, necessária à avaliação das consequências negativas ao ambiente nos empreendimentos.

Para Aragão (2008), o Princípio da Precaução não é um motivo de estagnação ou bloqueio do desenvolvimento científico, mas, pelo contrário, uma fonte de progresso científico. No mesmo sentido, sustenta Oliveira (2020) que o Princípio da Precaução não é obstáculo ao desenvolvimento ou para a inovação tecnológica, vez que pretende apenas reorientá-la para a manutenção do bem-estar coletivo. 
O Estado, ao aplicar o Princípio da Precaução preserva os recursos naturais para as presentes e futuras gerações. Desse modo, o Estado não se torna inimigo do desenvolvimento ao aplicar o princípio de forma proporcional. O Estado agindo assim, fomenta a descoberta de novas tecnologias mais limpas e baratas e a preservar a exploração por mais tempo em benefício de toda a coletividade (WEDY, 2009).

De acordo com Borile, Arnold e Calgaro (2019), deve-se ter presente, sobretudo, que:

\begin{abstract}
A solução para as questões ambientais não pode ser deduzida da letra fria da lei, nem de uma concepção individualista do conflito, mas com uma visão interdisciplinar da tutela do meio ambiente, com análise do caso concreto, sopesamentos e debates a fim de se obter uma solução eficaz das contendas ambientais. (BORILE; ARNOLD; CALGARO, 2019, p. 147)
\end{abstract}

O Princípio da Precaução surgiu como uma manifestação de prudência, tendo em vista os novos riscos criados pela humanidade. O princípio em comento atua no sentido de que a incerteza científica não seja empregada/usada como desculpa para que nenhuma ação seja tomada. Ou seja, havendo risco de dano grave, de difícil ou impossível reparação, mesmo que sem comprovação científica, faz-se necessária a adoção de medidas precaucionais.

O Princípio da Precaução é importante ferramenta na defesa do meio ambiente, ao se constatar que a reparação e a restauração são meios inadequados quando se trata de meio ambiente, pois uma vez concretizado o dano, é muito difícil, ou mesmo impossível voltar ao estado anterior. Da mesma forma, valores pecuniários não são equivalentes. Logo, demonstrase que o Princípio da Precaução, ao permitir a adoção de medidas de antecipação é importante instrumento de tutela do meio ambiente.

\title{
5 Considerações finais
}

O ambiente é alvo das preocupações mundiais, pois desde os primórdios, o homem degradou o ambiente, causando diversos reflexos negativos. A constante degradação do meio ambiente gera insegurança na população que vive circundada pelo temor aos riscos.

A vasta legislação em torno da questão ambiental, produz a falsa impressão de preservação ambiental, no entanto, observa-se que a legislação não garante a proteção do ambiente, além de não regular todas as situações. Nesse cenário, os princípios possuem ampla relevância, vez que orientam o sistema. O Princípio da Precaução, nesse seguimento, não consta de forma expressa na Constituição Federal, entretanto, pode ser deduzido do dever geral de preservação ambiental do texto constitucional, além de constar em diversas legislações infraconstitucionais. 
Observa-se que uma vez lesado o meio ambiente, torna-se muito difícil, ou mesmo impossível voltar ao estado anterior. Da mesma forma, valores pecuniários não se mostram equivalentes, vez que o ambiente não possui valoração monetária. Tendo em vista as características peculiares do meio ambiente, indispensável que os danos sejam evitados.

As medidas preventivas ganham cada vez mais relevância quando se constata que medidas repressivas e reparatórias se mostram ineficazes na defesa do meio ambiente. Assim, a maneira mais efetiva de preservar o meio ambiente é evitando que os danos ambientais ocorram, de tal modo, o Princípio da Precaução demonstra-se como importante mecanismo na defesa do meio ambiente.

Em que pese os argumentos contrários ao emprego do Princípio da Precaução, por ser considerado entrave ao desenvolvimento da ciência e tecnologia e por estagnar o crescimento econômico, tais afirmações não se sustentam. O Princípio da Precaução não é obstáculo ao desenvolvimento e à tecnologia, pois visa apenas reorientá-los para a manutenção do bem comum.

Ademais, deve-se ter presente que precaução importa em agir com moderação, ou seja, dentre os meios hábeis para evitar o risco de dano, deve-se optar pelos menos gravosos, àqueles que terão seus interesses atingidos. Assim, a ponderação de valores e o princípio da proporcionalidade são instrumentos para a segura implementação do princípio de precaução.

É possível constatar que, nem mesmo a incerteza científica pode ser tomada como desculpa para que nenhuma atitude seja adotada diante dos riscos de danos. O Princípio da Precaução obriga que medidas sejam tomadas a fim de preservar o meio ambiente, mesmo que para isso, haja conflito com outros direitos e valores. Assim, demonstra-se que o Princípio da Precaução, ao permitir a adoção de medidas de antecipação que evitem danos ambientais, é importante instrumento de tutela do meio ambiente.

\section{Referências}

ANTUNES, Paulo de Bessa. Direito Ambiental. 16. ed. São Paulo: Atlas, 2014.

ARAGÃO, Alexandra. Princípio da Precaução: manual de instruções. Revista do Centro de Estudos de Direito do Ordenamento, do urbanismo e do Ambiente, Coimbra, Faculdade de Direito da Universidade de Coimbra, Ano XI, v. 2, n. 22, p. 9-57, fevereiro, 2008.

BECK, Ulrich. Sociedade de Risco: rumo a uma outra modernidade. Tradução de Sebastião Nascimento. São Paulo: Editora 34, 2012.

BELLO FILHO, Ney de Barros. Teoria do Direito e Ecologia: apontamentos para um direito ambiental do século XXI. In: FERREIRA, Heline Sivini; LEITE, José Rubens Morato (org.). 
Estado de Direito Ambiental: tendências: aspectos constitucionais e diagnósticos. Rio de Janeiro: Forense Universitária, 2004.

BENJAMIM, Antônio Herman. Direito Constitucional Ambiental Brasileiro. In:

CANOTILHO, José Joaquim Gomes Canotilho; LEITE, José Rubens Morato (org.). Direito

Constitucional Ambiental Brasileiro. 2. ed. São Paulo: Saraiva, 2008.

BORILE, Giovani Orso; ARNOLD, Cláudia de Moraes; CALGARO, Cleide. A tutela de urgência no âmbito do processo ambiental: efetivação do Princípio da Precaução. Revista do Direito Público, Londrina, v. 14, n. 2, p. 136-150, agosto, 2019. DOI: 10.5433/24157108104-1.2019v14n2p. 136. ISSN: 1980-511X.

DA SILVA, José Afonso. Direito Ambiental Constitucional. 6. ed. São Paulo: Malheiros Editores, 2007.

LEFF, Enrique. Saber ambiental: sustentabilidade, racionalidade, complexidade, poder. Tradução de Lúcia Mathilde Endlich Orth. Petrópolis: Editora Vozes, 2001.

LEITE, José Rubens Morato; AYALA, Patryck de Araújo. Dano Ambiental: do individual ao coletivo extrapatrimonial: teoria e prática. 6. ed. São Paulo: Editora Revista dos Tribunais, 2014.

LEITE, José Rubens Morato. Sociedade de risco e Estado. In: CANOTILHO, José Joaquim Gomes Canotilho; LEITE, José Rubens Morato (Orgs.). Direito Constitucional Ambiental Brasileiro. 2. ed. São Paulo: Saraiva, 2008.

LOPEZ, Teresa Ancona. Princípio da Precaução e Evolução da Responsabilidade Civil. São Paulo: Quartier Latin, 2010.

LORENZETTI, Ricardo Luis. Teoria Geral do Direito Ambiental. Tradução de Fábio Costa Morosini e Fernanda Nunes Barbosa. São Paulo: Revista dos Tribunais, 2010.

LUNELLI, Carlos Alberto. É preciso querer salvar o ambiente. In: RECH, A. U.; MARIN, J.; AUGUSTIN, S. (Orgs.). Direito Ambiental e Sociedade. Caxias do Sul: Educs, 2015.

MACHADO, Paulo Affonso Leme. Direito Ambiental Brasileiro. 22. ed. São Paulo: Malheiros Editores, 2014.

MATEO, Ramón Martin. Tratado de Derecho Ambiental. Madrid: Editorial Trivium, 1991.

MAZUR, Arielli Straube; MOURA, Analice Schaefer de. Princípio da Prevenção e da Precaução e o dano ambiental futuro no caso Mariana/MG de 2015. Revista Científica Eletrônica Academia de Direito, v. 1, n. 1, p. 211-233, dezembro, 2019.

MIRRA, Álvaro Luiz Valery. Ação civil pública e a reparação do dano ao meio ambiente. 2. ed. São Paulo: Editora Juarez de Oliveira, 2004.

NOGUEIRA, Ana Carolina Casagrande. O conteúdo jurídico do Princípio de Precaução no Direito Ambiental Brasileiro. In: FERREIRA, Heline Sivini; LEITE, José Rubens Morato 
(org.). Estado de Direito Ambiental: tendências: aspectos constitucionais e diagnósticos. Rio de Janeiro: Forense Universitária, 2004.

NOIVILLE, Christiane. Ciência, Decisão, Ação: três observações em torno do Princípio de Precaução. In: VARELLA, Marcelo Dias (org.). Governo dos riscos: Rede LatinoAmericana-Europeia sobre Governo dos Riscos. Brasília: Editora Unitar, 2005.

OLIVEIRA, André Soares. Modernidade e risco: fundamentos do Princípio da Precaução e desafios para responsabilidade civil. Revista Direito e Justiça: Reflexões Sociojurídicas, Santo Ângelo, v. 20, n. 36, p. 97-127, jan./abr. 2020 | DOI:

http://dx.doi.org/10.31512/rdj.v20i36.2920.

OST, François. A natureza à margem da lei: a ecologia à prova do Direito. Lisboa: Instituto Piaget, 1997.

PILATI, José Isaac. Propriedade e função social na pós-modernidade. Rio de Janeiro: Lumen Juris, 2011.

RIO DE JANEIRO. Declaração do Rio de Janeiro sobre Meio Ambiente e

Desenvolvimento. Estud. av., São Paulo, v. 6, n. 15, p. 153-159, ago. 1992. Disponível em: http://www.scielo.br/scielo.php?script=sci_arttext\&pid=S0103-

$40141992000200013 \& \operatorname{lng}=$ pt\&nrm=iso. Acesso em: $1^{\circ}$ jun. 2020.

SANTILLI, Juliana. Socioambientalismo e novos direitos. São Paulo: Petrópolis, 2005.

SILVEIRA, Clóvis Eduardo Malinverni da. O Princípio da Precaução como critério de avaliação de processos decisórios e políticas públicas ambientais. Revista Internacional de Direito Ambiental, Caxias do Sul, ano II, v. 2, n. 5. maio/ago. 2013.

SILVEIRA, Clóvis Eduardo Malinverni da. Políticas públicas e processos decisórios em matéria de biosseguranças face ao Princípio de Precaução. In: PEREIRA, A. O. K.;

CALGARO, C.; HORN, L. F. D. R. (org.). Resíduos sólidos, consumo, sustentabilidade e riscos ambientais. Caxias do Sul: Juris Plenun, 2014.

SILVEIRA, Clóvis Eduardo Malinverni da. Risco Ecológico Abusivo: a tutela do patrimônio ambiental nos Processos Coletivos em face do risco socialmente intolerável. Caxias do Sul: Educs, 2014.

THORSTENSEN, Vera; MOTA, Catherine Rebouças; ARIMA JR., Mauro Kiithi. O Princípio da Precaução na OCDE. Escola de Economia de São Paulo da Fundação Getúlio Vargas, Working Paper 515, CCGI nº 19, out. 2019.

WEDY, Gabriel. O Princípio Constitucional da Precaução: como instrumento da tutela do meio ambiente e da saúde pública. Belo Horizonte: Fórum, 2009. 